\title{
Milliinternational Unit per Square Meter
}

National Cancer Institute

\section{Source}

National Cancer Institute. Milliinternational Unit per Square Meter. NCI Thesaurus. Code C67409.

A dose calculation unit equal to one-thousandth (10E-3) of an arbitrary unit of biological activity (International Unit) of substance per square meter of body surface area. 